\title{
Abbreviations in English Military Terminology
}

\begin{abstract}
This article presents an overview of classification and taxonomic arrangement of abbreviations in English military terminology and analyzed from two perspectives - orthographic and morphological. Previous works in this field provide sometimes conflicting categorizations, thus showing a need for a more consistent approach and classification. The work aims to provide an outline of what a typical military abbreviation consists of and how it is created. The properties of abbreviations are analyzed in terms of their length, the length of their source phrases, source phrase elements used and omitted in the creation of abbreviations, and the elements used in their creation, i.e. initials and splinters. The abbreviations are grouped according to several criteria.
\end{abstract}

Key words

Abbreviations; acronyms; alphabetisms; blends; clippings; military terminology; morphology; orthography

\section{Introduction}

According to Algeo, shortening and blending are the third and the fourth most productive processes of forming neologisms respectively, and neologisms from the military lexicon were among the first recorded ones in 1941 (1991: 14-15). This underlines the importance of studying abbreviations, and we chose to analyze them in terms of their orthography and morphology.

Harley states that the first initialisms proliferated in the domain of American bureaucracy and then spread onto the American Army which showed a tendency to abbreviate a majority of new terms used (2006: 96-97). Since the military lexicon represents a productive part of the English vocabulary, due to an increasing 
number of weapons, technologies, and organizations, and since some of the first neologisms stem from it, the idea was to narrow down the scope of research to this particular field of English vocabulary. The work aims to provide answers to the following research questions:

1. How are letters and initials arranged in initialisms? Is the one-letter-per-onesource-phrase-constituent pattern used or are more irregular patterns of creation used?

2. What is the average number of letters in abbreviations? What is the ratio of initials/splinters in abbreviations and the number of constituents in source phrases?

3. What is the most common word class in initialisms, blends, and hybrid forms of clippings and initialisms, and their source phrases?

4. Are both lexical and function words used in the creation of abbreviations and which word type is omitted more often? How common are function words in the formation of abbreviations and why?

It was also our intention to test whether initialisms (alphabetisms and acronyms) are more numerous abbreviations in the military lexicon, as they are often used in highly specialized registers, whereas blends are more used with a jocular and attention-catching intent, and thus used in less formal registers. However, due to a limited and a somewhat arbitrary corpus selection, this question could not have been answered with complete certainty and requires further research in the field of formality of use.

\section{Terminology and classification}

One of the rare properties of abbreviations that most authors agree upon are the discrepancies in their typologies and a lack of clear-cut borders between categories. López Rúa states that there is a great deal of inconsistency even between what an acronym in general is and what proper abbreviation, a clipping, a blend or a hybrid, including features of two or more of the above are (2004: 110). Cannon (1989) notes how some of the earlier attempts of classification and systematization in this field brought only more confusion as authors often included certain blends and clippings into their corpuses of acronyms. Gale's dictionaries, for instance, elicit some textbook examples of blends (like motel, brunch and smog) as acronyms and not blends (Crowley and Sheppard 1987, Sheppard and Towell 1987). Similar examples of historically wrongly classified abbreviations are listed in Fischer's work as well (1998: 28). Another reason for this confusion, according to Cannon (1989), is the dictionary practice of listing various types of contracted word forms into the category of abbreviations since the fifteenth century, and this confusion was continued in the twentieth century. 


\subsection{Inconsistency in terminology and classification of abbreviations}

The lack of consistency has been highlighted in recent times even more. The proliferation of "modern" abbreviations from areas such as computer and technical sciences, military, governmental and non-governmental agencies, and even various modes of electronic communication, such as instant messaging and text messaging, blurred the borders between the categories even further (López Rúa 2007).

Another discrepancy within this field may be observed in the name of the process, or better, the processes by which the abbreviations are created. Authors mostly agree that abbreviations do not fall into the field of traditional morphology, since the elements used in their creation are units smaller than morphemes. Because of this, Plag (2003) distributes the abbreviations into two distinct processes of "derivation without affixation". Since prosodic features play a more vital role in the creation of blends and clippings they belong to the "prosodic morphology", while orthography is considered more vital for the creation of initialisms and alphabetisms. Still, both groups have a loss of certain word elements in common, unlike adding new material to words, as is the case with affixation. Alternatively, in works of Fandrych (2008a, 2008b) and López Rúa (2006), the process by which abbreviations are created is named "non-morphological word formation". Fandrych, however, adds an additional term to this process which we deem more appropriate - "submorphemic word formation", which implies that the elements involved are smaller than morphemes, while the former term would imply that there are not any morphemes involved at all. The elements used in the creation of abbreviations are thus initials for initialisms, which Fandrych denotes as acronyms, and splinters for blends and clippings (2008a). Thus, the most appropriate general term for all words created through truncation of some kind seems to be abbreviations, since all constituent words are abbreviated, in one way or the other.

\subsection{Simple and complex shortenings}

The taxonomy of abbreviations in our work is taken from López Rúa's work (2004: 123-124), who elicits works of Kreidler (1979), Quirk et al. (1985) and Algeo (1991) as sources of her taxonomy. On a general level, she makes a distinction between simple and complex shortenings. Complex shortenings are those which occur in both written and spoken form, i.e. initialisms, blends and clippings. Simple shortenings are those that can be found only in written form, while in the spoken language they appear in the form of their full phrases, i.e. as proper abbreviations, such as prof., dr., and Mr. López Rúa (2006) states that the combination of some of these abbreviations can lead to them evolving to complex types of abbreviations, i.e. blends, clippings and initialisms.

Complex shortenings include three main groups - blends, clippings and initialisms, with the latter comprising acronyms and alphabetisms. The group of alphabetisms, i.e. the group involving both items "spoken as individual letters" and "pronounced as single words" (Crystal 1995: 120), seems to be the most trou- 
blesome, as this is where the opinions of many authors diverge. Cannon (1989) and Harley (2006) use the same term - initialisms, but they divide the group into acronyms and abbreviations, and the latter term seems more suitable to be the "umbrella term" for all words created in this fashion because, in our opinion, it denotes the main property of its subgroups, i.e. the words created by abbreviating words and phrases. Plag (2003) uses the same terms as Cannon and Harley, but he makes abbreviations superordinate to initialisms and acronyms. Jackson and Zé Amvela (2005) use the same subordinate terms as Plag - acronyms and initialisms, but they use the term shortenings to be the superordinate term of this group, which includes clippings and aphetic forms ('cause < because). Crystal (1995) and Stockwell and Minkova (2001) do not follow the practice of providing different terms for superordinate and subordinate terms. Instead, they use initialisms and acronyms, with the acronyms being the subgroup of the initialisms in Crystal's work, and the initialisms being the subgroup of acronyms in Stockwell and Minkova's work. In her two works, Fandrych proposes a distribution similar to Stockwell's, i.e. acronyms and abbreviations, with acronyms as the superordinate term for the group $(2008 ; 2008 \mathrm{a})$. Interestingly, in Fandrych's classification initialisms are not mentioned.
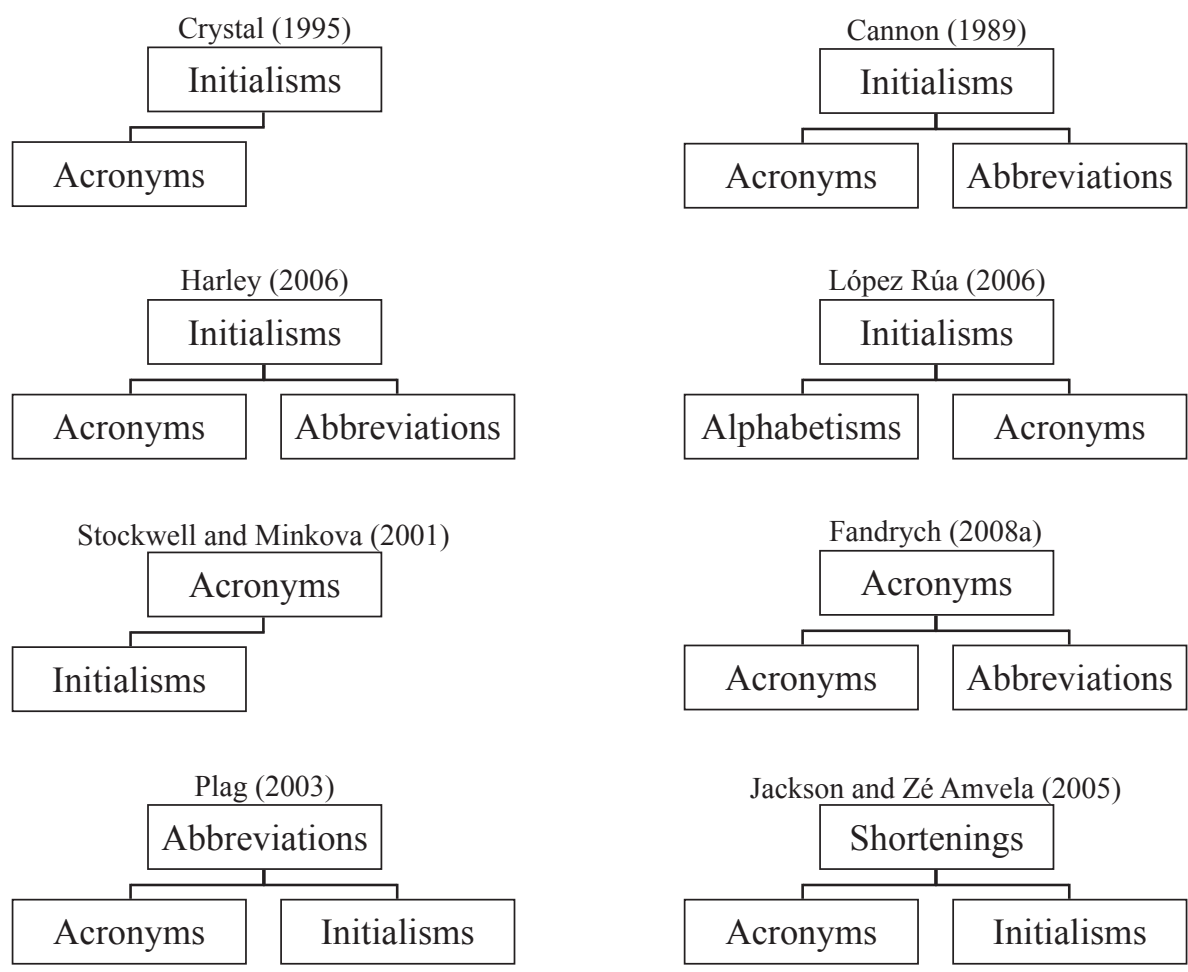

Figure 1. An overview of taxonomies for initialisms, alphabetisms and acronyms of cited authors 


\subsection{A tentative taxonomy of abbreviations}

Ultimately, López Rúa (2006) divides abbreviations into two mentioned groups of complex and simple shortenings, with the former divided into clippings, blends and initialisms, and the last group into alphabetisms and acronyms. Simple shortenings occur only in written form and encompass proper abbreviations. It should be noted that almost all authors covered place blends and clippings into shortenings, with the exception of Jackson and Zé Amvela who regard them separately from other abbreviations.

We consider López Rúa's approach to be the most appropriate way of classifying abbreviations, especially the groups of acronyms and alphabetisms, for three main reasons. Firstly, we find it important for superordinate and subordinate terms to be different so as to avoid confusion. Secondly, the chosen terms should fit the properties of the named category; which in case of the term initialism denotes that the words of the category are created from initial letters of the constituent words and phrases, and the alphabetism denotes that the members of the category are pronounced letter by letter. Thirdly, despite their presence in written medium only, the group of proper abbreviations should not be ignored or confused with other types of abbreviations, as was the case not only with earlier dictionary practice, but some contemporary works as well. For instance, Cannon mentions the case of eliciting D.B.S. 'de bonis suis' as an abbreviation, whereas Plag denotes the proper abbreviations BSc 'Bachelor of Science', Inc. 'Incorporated', Norf. 'Norfolk', Ont. 'Ontario', and kHz 'kilohertz' as abbreviations.

According to López Rúa, an initialism is "the result of selecting the initial letter, or occasionally the first two letters, of the orthographic words in a phrase and

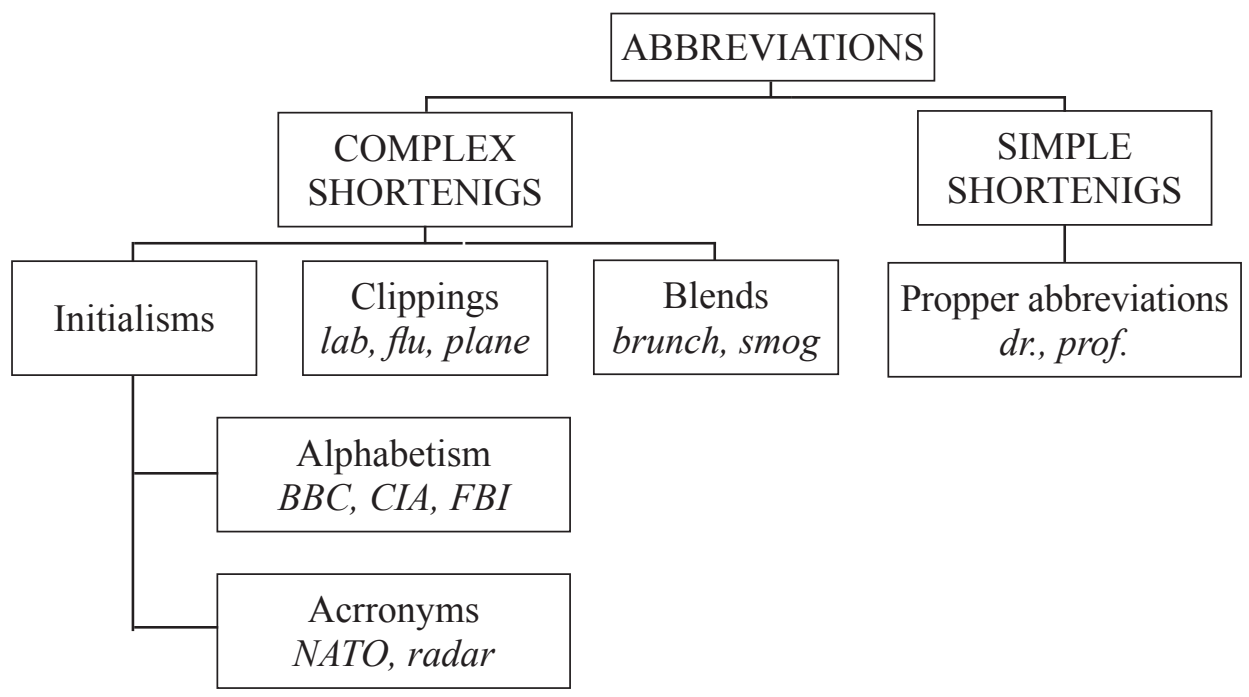

Figure 2. Taxonomy of abbreviations by López Rúa used in this work 
combining them to form a new sequence." Pronunciation of the words created in this fashion depends on various linguistic factors, but the two major ways for these words to be pronounced are either as a word (prototypical acronyms) or as a series of letter names (prototypical alphabetisms) (2006: 677). There are also some examples of initialisms being pronounced in both ways (VAT/Vat from 'Value Added Tax') and as a combination of the two (CD-ROM from 'compact disc readonly memory'), but these are far less frequent ways of pronunciation. Clipping is described as a "process by which a word-form of usually three or more syllables is shortened without a change in meaning or functions" (2006: 676). These abbreviations are somewhat arbitrary regarding the part of the word that gets truncated, and although they have informal connotations, there are examples of clippings replacing their source phrase (bus $<$ omnibus). The last type of complex abbreviations, i.e. blends, is created by joining two or more word-forms through simple concatenation or overlap and then by shortening at least one of them (2006: 677).

It can be seen that any attempt at defining and categorizing abbreviations stands on weak ground, as authors tend to name and classify those relatively "purer" abbreviations in different ways (by "purer" we mean those which distinctly belong to a single clear-cut category, rather than displaying features of two or more abbreviation types). Another problem is that some abbreviation types are very elusive and many of them exhibit hybrid features, i.e. characteristics of several abbreviated forms. However, they have some properties in common and these shared characteristics will provide the basis for our work.

\section{Corpus analysis}

The research was conducted on a limited corpus of abbreviations taken from the $3^{\text {rd }}$ edition of Richard Bowyer's Dictionary of Military Terms. Not all abbreviations from the dictionary were used in the corpus, as a corpus encompassing all abbreviations would have made this work far too large for a single article. The abbreviations were selected in such a way that they are among the most commonly used ones and that they represent different fields of military terminology and are thus representative of the military lexicon. The corpus comprises 121 abbreviations, distributed into two major abbreviation types - initialisms and blends. Initialisms are represented with 89 examples -52 alphabetisms and 37 acronyms, while blends are represented with 23 examples. There are also nine examples of abbreviations which are created through a combination of clipping and initialism and are dealt with separately. The abbreviations of the corpus are predominantly nouns -109 , while there are five adjectives, three verbs, one adverb and three abbreviations that can be considered both as adjectives and adverbs. The list of abbreviations analyzed in our work is given in the appendix, distributed into three mentioned types in the following order: initialisms, blends, and the hybrid combination of clippings and initialisms along with their full forms of source phrases. 
Of the abbreviations in the corpus, the initialisms are used in the most lexical fields of military lexicon, ranging from weaponry and technology, rank, logistics, training, to organization and operations in the field. Blends are limited to several fields: equipment and technology, military organization and procedures, while abbreviations created through clipping and initializing are limited to two semantic fields - organization and technology.

The corpus is analyzed on two levels - orthographic and morphological. Orthographic level deals with the number of elements of abbreviations and their source phrases (average number and patterns of arrangement of initials and splinters and their ratio to source phrase constituents), as well as the ways of their graphic presentation, while the morphological level considers the word classes of abbreviations and their source phrase elements, and the usage or omission of lexical and function words.

To our knowledge, the only approach similar to the one in this work can be found in Cannon's work (1989), which deals exclusively with initialisms. In addition, some works focus on various aspects of just one type of abbreviation, such as Gries (2004a, 2004b), whereas the other works deal with abbreviations from various other perspectives, such as semantics (Lehrer 1998), productivity (Bauer 2003, Lehrer 2007), taxonomy (López Rúa 2004), or from an interdisciplinary perspective (Fandrych 2008). However, the core approach of this work is not taken from any of the previous works. One of the aims was to show how different previous approaches to the classification of abbreviations make their analysis more difficult, and, by comparing them, to see which principle in their classification would be the most appropriate one.

\subsection{Orthographic analysis}

The main scope of the orthographic analysis is to determine the patterns of arrangement of letters and initials/splinters in abbreviations and the ratio of initials or splinters to source phrase constituents (research questions 1 and 2, cf. §1). The length and arrangement of these elements in their respective abbreviations is analyzed in order to provide a different perspective than that given through the analysis of the number of letters, i.e. to show the usage of elements considered essential in the creation of respective abbreviation types. In the analysis of source phrases, compounds such as 'anti-aircraft' in AAA 'anti-aircraft artillery' and 'take-off' in VTOL 'vertical take-off and landing' are counted as one word.

Among the criteria used in the analysis of our corpus, two are applied for all abbreviations, as they can be examined in all four abbreviation types, while some additional criteria are applied individually. The following criteria are applied for all abbreviation types:

- their length, in terms of number of letters used; and

- the length of their source phrase, in terms of number of source phrase constituents. 
The additional criteria for initialisms are:

- the relation between the length and the number of source phrase constituents; and

- the size and arrangement of initials.

The pronunciation is also analyzed for acronyms, while such analysis for alphabetisms is deemed superfluous since their definition states they are pronounced letter by letter.

The additional criteria for blends are:

- size and relation of splinters; and

- omission of elements.

There is just one additional criterion for clippings and initialisms - the arrangement of splinters. Each of the categories created by these criteria is followed up by five examples or less if the category has less than five examples. The only exception is the second criterion, the source phrase length, which is limited to a single example for brevity's sake.

The reason the mentioned criteria are used is to show various properties of each abbreviation type - the range of length and the most common length, parts of source phrases used in each abbreviation type, the relation between the abbreviation length and source phrase length and the size and arrangement of initials and splinters.

Other orthographic aspects taken into consideration are the usage of capital and lower case letters, and the usage of symbols other than letters. The analysis of our corpus reveals that all abbreviations are written entirely in capital letters, meaning most of them have not been lexicalized yet, with the exception of C-in-C 'Commander in Chief' and L of C 'line of communication' in which the prepositions connecting the two source phrase parts are written in lower case. There are some examples of abbreviations with non-letter characters, such as numeric or typographic symbols (Cannon 1989: 108-110) and there are two such examples of abbreviations in our corpus $-\mathrm{R} \& \mathrm{R}$ 'rest and recuperation' using the ampersand symbol, and METT-T 'mission, enemy, terrain, troops available, time' using the hyphen. It is our opinion that the hyphen is used instead of the letter " $\mathrm{A}$ " to make this abbreviation, which serves as a mnemonic device for officers, more comprehensible and as short as possible. Had the form METTT been used, the third ' $T$ ' would probably often be forgotten as the pronunciation of METTT would be [met], identical to the pronunciation of METT, thus causing an occasional omission of the last ' $\mathrm{T}$ '.

There are other similar examples of abbreviations using such symbols which are not included in this corpus for brevity's sake, such as 2IC 'second in command, AAV-7A1 'amphibious assault vehicle seven', AEW \& C 'airborne early warning and control', $\mathrm{L} / \mathrm{Cpl}$ 'lance corporal' and P-INFO 'public information. It should be noted that the usage of numerical symbols is very prominent in the field of weaponry and vehicles, e.g. A-4, A-10, B-1, B-52, F-22, Mi-35, etc. However, these forms refer to various models of certain weapons and vehicles, without a full form they refer to. 


\subsubsection{Orthographic analysis of alphabetisms}

The most common alphabetisms in our corpus are the 3-letter ones, encountered in 35 examples (67.35\% of alphabetisms), followed by 4-letter (21.15\%), 2-letter $(9.62 \%)$ and 5-letter alphabetisms (1.92\%). Their average length (the sum of all letters in all abbreviations divided by the number of abbreviations) is 3.15 letters. The ones shown below are the examples of their respective categories:

\section{2-letter alphabetisms \\ 3-letter alphabetisms \\ 4-letter alphabetisms \\ 5-letter alphabetism}

IO, IR LZ, PO, XO

AAA, DOA, EOD, MIA,WMD

ATGW, CINC, CSAR, ECCM, MAOT $\mathrm{ABCCC}$

The most common length of source phrase is three words, encountered in 33 abbreviations (63.46\%), followed by 4-word source phrases (17,31\%), 2-word source phrases (13.46\%) and 1-word, 5-word and 7-word source phrases, comprising $1.92 \%$ each. The average length of alphabetism source phrase is 3.12 words. The examples are:

1-word alphabetism source phrase 2-word alphabetism source phrase 3-word alphabetism source phrase 5-word alphabetism source phrase 4-word alphabetism source phrase

7-word alphabetism source phrase 'infrared' 'intelligence officer'

'Army Air Corps'

'combat search and rescue'

'airborne command, control and communications'

'Organization of Security and Cooperation in Europe'

When contrasting the length of each alphabetism with its number of source phrase constituents, we may distribute them into three distinct categories: a) alphabetisms with more letters than source-phrase constituents, comprising nine alphabetisms (17\%); b) alphabetisms with equal number of letters and source phrase constituents, comprising 39 alphabetisms (75\%); and c) alphabetisms with fewer letters than source phrase constituents, comprising four alphabetisms $(8 \%$, see Figure 3).

From this it would seem that for the majority of alphabetisms analyzed in this corpus each source phrase constituent is represented by one letter, with the exceptions to this rule making up for $25 \%$ of alphabetisms. However, if we examine the length of alphabetisms in terms of the number of initials, we come to a different distribution. Since initials may consist of one or two letters, the alphabetisms may be distributed into alphabetisms in which the number of letters coincides with the number of initials, i.e. alphabetisms in which each source phrase constituent used in the abbreviation is represented by a single letter, and alphabetisms in which there are more letters than initials, i.e. alphabetisms in which source phrase 


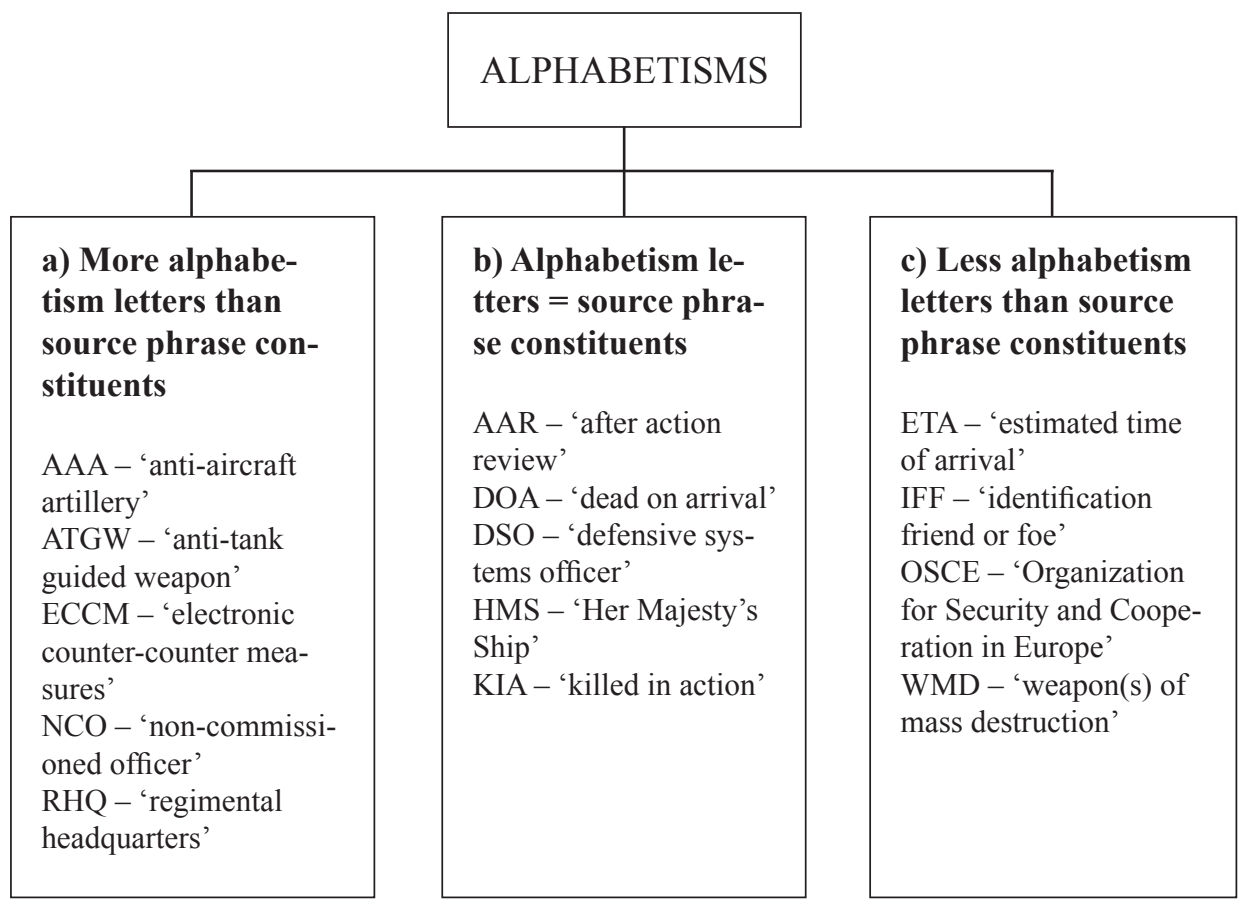

Figure 3. Distribution of alphabetisms according to the ratio of their length and number of source phrase constituents

constituents can be represented by two letters. The majority of alphabetisms in this corpus (41) use one letter per source phrase constituent, while there are 11 of those which use two letters per constituent. Those which use two-letter initials are further categorized into alphabetisms in which the two-letter initial is placed a) in the initial position; b) in the middle position; and c) in the final position, as shown in Figure 4:

These alphabetisms can be further divided into three subgroups according to the source of the two-letter initial:

- alphabetisms with a compound in the source phrase connected by a hyphen, taking one letter from each part of a compound ( 6 alphabetisms), e.g. AAA 'antiaircraft artillery', AAM 'air-to-air missile', ATGW 'anti-tank guided weapon', ECCM 'electronic counter-counter measures', NCO 'non-commissioned officer';

- alphabetisms in which two letters from a single source phrase word are taken (3 alphabetisms) - ABCCC 'airborne command, control and communications', IR 'infrared' and RHQ 'regimental headquarters'; and

- alphabetisms in which a preposition connecting the two source phrase constituents is not abbreviated at all (2 alphabetisms) - CINC/C-in-C 'Commander in Chief' and L of C 'line of communication'. 


\begin{tabular}{|c|c|c|}
\hline \multicolumn{3}{|c|}{$\begin{array}{c}\text { ALPHABETISMS WITH MORE LETTERS } \\
\text { THAN INITIALS }\end{array}$} \\
\hline $\begin{array}{l}\text { a) two-letter initial } \\
\text { in the initial posi- } \\
\text { tion }\end{array}$ & $\begin{array}{l}\text { b) two-letter initial } \\
\text { in the central posi- } \\
\text { tion }\end{array}$ & $\begin{array}{l}\text { c) two-letter initial } \\
\text { in the final } \\
\text { position }\end{array}$ \\
\hline $\begin{array}{l}\text { AAA - ' 'anti-aircraft } \\
\text { artillery' } \\
\text { AAM - 'air-to-air mi- } \\
\text { ssile' } \\
\text { ABCCC - 'airborne } \\
\text { command, control and } \\
\text { communications' } \\
\text { ATGW - 'anti-tank } \\
\text { guided weapon' } \\
\text { IR - 'infrared' }\end{array}$ & $\begin{array}{l}\text { CINC - 'Commander } \\
\text { in } \underline{C} \text { hief' } \\
\text { ECCM - 'electronic } \\
\text { counter-counter mea- } \\
\text { sures' } \\
\text { L of C - 'line of com- } \\
\text { munication' } \\
\text { VTOL - 'vertical take- } \\
\text {-off and landing' }\end{array}$ & $\begin{array}{l}\text { RHQ - 'regimental } \\
\text { headquarters' }\end{array}$ \\
\hline
\end{tabular}

Figure 4. Distribution of alphabetisms with two-letter initials according to arrangement of initials

Also, while alphabetisms, and acronyms for that matter, sometimes use the first one or two letters of the source phrase constituents, there is an example in our corpus of an alphabetism using only the second letter of the source phrase constituent - XO 'executive officer'. It is our opinion that this is done to facilitate comprehension - one may connect the letter ' $\mathrm{x}$ ' to 'executive' with more ease than one would with the letter ' $\mathrm{e}$ '. This is the only example of an abbreviation using the second letter of the source phrase constituent and omitting the first.

\subsubsection{Orthographic analysis of acronyms}

The most common length of acronyms is four letters $(45.95 \%)$, followed by five letters $(27.03 \%)$, three letters $(13.51 \%)$, six letters $(8.11 \%)$ and seven and eight letters $(2.78 \%$ each), while the average acronym length is 4.49 letters.

3-letter acronyms

4-letter acronyms

5-letter acronyms

6-letter acronyms

7-letter acronym

8-letter acronym
HOT, JAG, ROM, TOW, WAC AWOL, DMPI, FLOT, FROG, HALO

AWACS, DIBUA, FAARP, FIBUA, MILES

JSTARS, SACLOS, SALUTE

ANGLICO

SERPACWA 
The most common length of acronym source phrase is four words, shown in 12 examples $(32.43 \%)$, followed by the length of three words $(29.73 \%)$, five words $(16.22 \%)$, six words $(13.51 \%)$, seven words $(5.41 \%)$ and eight words $(2.70 \%)$, while the average length is 4.53 words. By comparing these values to those for alphabetisms, we may see that the average acronym of this corpus is longer than the average alphabetism by 1.34 letters, while the average acronyms' source phrase is longer by 1.41 words.

3-word acronym source phrase 4-word acronym source phrase 5-word acronym source phrase 6-word acronym source phrase

7-word acronym source phrase

8-word acronym source phrase 'absent without leave'

'defence in built-up areas'

'forward arming and refuelling point' 'mission, enemy, terrain, troops available, time'

'joint, surveillance and targeting attack radar system'

'skin exposure reduction paste against chemical warfare agents'

Like alphabetisms, the acronyms of our corpus are also divided into three distinct groups by contrasting their length and the number of their source phrase constituents: a) acronyms with more letters than source-phrase constituents, comprising

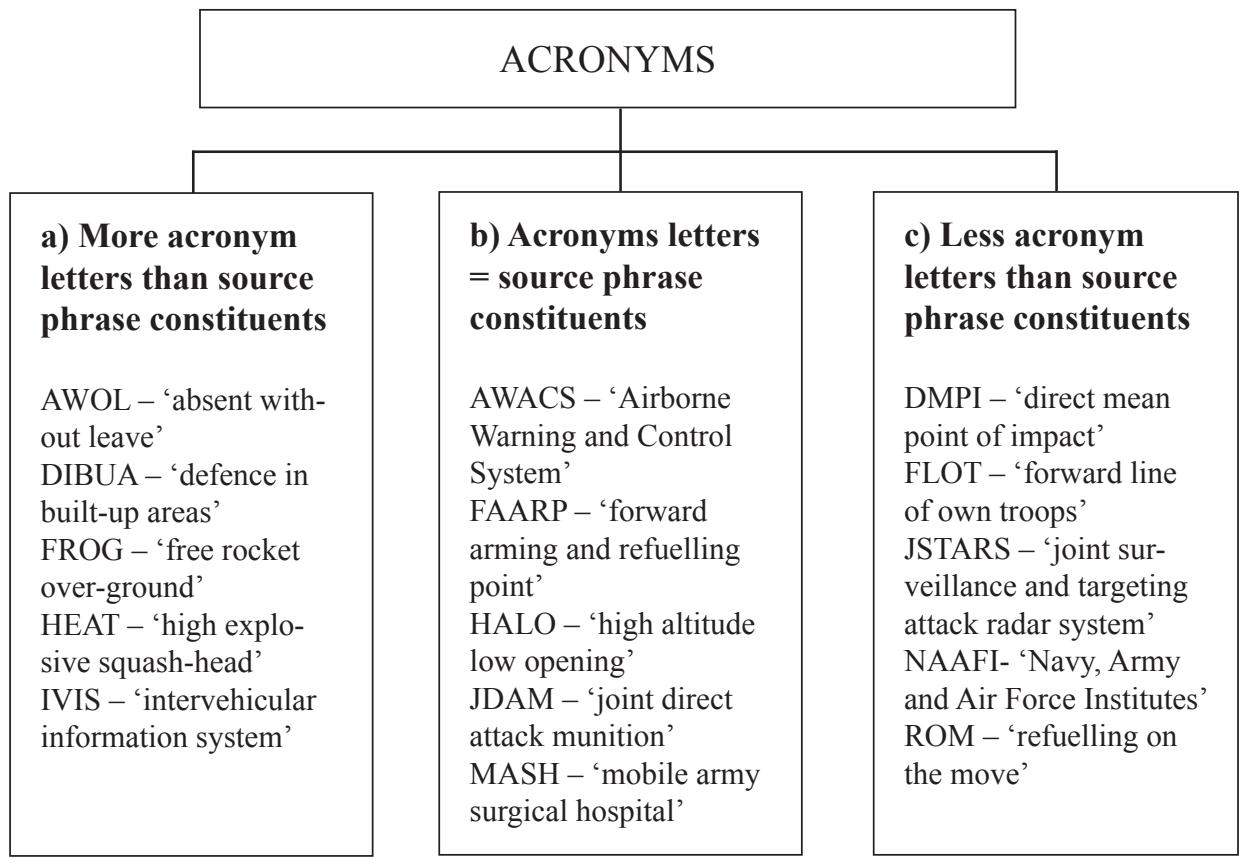

Figure 5. Distribution of acronyms according to the ratio of their length and number of source phrase constituents 
13 acronyms (35\%); b) acronyms with equal number of letters and source phrase constituents, comprising 15 acronyms (41\%); and c) acronyms with less letters than source phrase constituents, comprising nine acronyms (24\%).

Like alphabetisms, acronyms of our corpus can be further divided into a) those in which each source phrase constituent is represented by a single letter, i.e. the number of letters is the same as the number of initials, comprising 23 acronyms, and $b$ ) those in which source phrase constituents can be represented by two-letter initials, i.e. those in which there are more letters than initials, comprising 14 acronyms. The ratio of those acronyms in which two-letter initials are used (37.8\%) is slightly higher than that for alphabetisms (21\%). The acronyms with two-letter initials are also distributed according to the position of the two-letter initial, as shown in Figure 6.

These acronyms with two-letter initials can be further divided into two groups according to the source of the two-letter initials:

(a) acronyms with a compound in the source phrase connected by a hyphen, taking one letter from each part of a compound (10 acronyms), e.g. DIBUA 'defence in built-up areas', FIBUA 'fighting in built-up areas', HARM 'high-speed anti-radiation missile', HEAT 'high explosive anti-tank' and LRRP 'long-range reconnaissance and patrolling'; and

(b) acronyms in which two letters from a single source phrase word are taken (four acronyms) - ANGLICO 'air naval gunfire liaison company', AWOL 'ab-

\begin{tabular}{|c|c|c|}
\hline \multicolumn{2}{|c|}{$\begin{array}{c}\text { ALPHABETISMS WITH MORE LETTERS } \\
\text { THAN INITIALS }\end{array}$} & ERS \\
\hline $\begin{array}{l}\text { a) 2-letter initial in } \\
\text { the initial position }\end{array}$ & $\begin{array}{l}\text { b) } 2 \text {-letter initial in } \\
\text { the central position }\end{array}$ & $\begin{array}{l}\text { c) } 2 \text {-letter initial in } \\
\text { the final position }\end{array}$ \\
\hline $\begin{array}{l}\text { ALARM - 'air- } \\
\text { launched anti-radiation } \\
\text { missile' } \\
\text { ANGLICO - 'air-naval } \\
\text { gunfire liaison com- } \\
\text { pany' } \\
\text { IVIS - 'intervehicular } \\
\text { information system' } \\
\text { LRRP - 'long-range } \\
\text { reconnaissance and } \\
\text { patrolling' } \\
\text { SACLOS - 'semi- } \\
\text { automatic commandline } \\
\text { of sight' }\end{array}$ & $\begin{array}{l}\text { AWOL - 'absent wit- } \\
\text { hout leave' } \\
\text { DIBUA - 'defence in } \\
\text { built-up areas' } \\
\text { FIBUA - 'fighting in } \\
\text { built-up areas' } \\
\text { HARM - 'high-speed } \\
\text { anti-radiation missile' } \\
\text { IAAG - 'improvised } \\
\text { anti-armour grenade' }\end{array}$ & $\begin{array}{l}\text { FROG - 'free rocket } \\
\text { over-ground' } \\
\text { HEAT - 'high explos- } \\
\text { ive anti-tank' } \\
\text { HESH - 'high explos- } \\
\text { ive squash-head' }\end{array}$ \\
\hline
\end{tabular}

Figure 6. Distribution of acronyms with two-letter initials according to arrangement of initials 
sent without leave', IVIS 'intervehicular information system' and SEAL 'sea, air, land'. It is our opinion that the motivation for the inclusion of additional elements is, similarly to such examples with alphabetisms, facilitation of pronunciation and comprehension.

Regarding pronunciation, there are some acronyms which blur the line between the two categories of initialisms, and such categories are mentioned by Cannon (1989) and López Rúa (2006). DMPI ['dimpi] and LRRP [13:p] represent those abbreviations that appear to be alphabetisms, but are actually acronyms and are pronounced as single words (Cannon 1989), while JDAM ['dzeIdæm], JSTARS [1dzer sta:z] and METT-T [,met'ti:] are pronounced as a combination of the two types of initialisms, i.e. alphabetisms and acronyms (López Rúa 2006).

\subsubsection{Orthographic analysis of blends}

The blends of this corpus are mostly five letters long (39.13\%), followed by 6-letter $(30.43 \%)$, 7-letter $(21.74 \%)$, and 8 -letter blends $(8.70 \%)$, while their average length is six letters, e.g.:

\section{5-letter blends AVGAS, ELINT, EUCOM, MAPEX, MILOB 6-letter blends COMCEN, HUMINT, INTSUM, PSYWAR, PSYOPS 7-letter blends BRITFOR, CASEVAC, CENTCOM, MEDEVAC, OPSCHED 8-letter blends INMARSAT, STRATCOM}

The most common length of their source phrases is two, accounting for $86.96 \%$ blends, while the length of three words comprises the remaining $13.04 \%$. The average source phrase length is 2.13 words. It should be noted that among the three abbreviations (see below) with three source phrase constituents the only one that uses all three constituents is INMARSAT 'international maritime satellite', while the other two omit the third element. Another interesting example is PSYOPS, which uses the first two letters and the last letter of its second source phrase constituent 'operations', being the only blend exhibiting such behaviour.

2-word blend source phrases

'aviation gasoline, British Force'

3-word blend source phrases

'end of exercise, international maritime'

'satellite, tactical satellite radio'

When we examine the blends with regard to the size of splinters they may be divided into three groups: a) blends in which the first splinter is longer than the second, comprising six blends (26\%); b) blends in which the splinters are of equal length, comprising eight blends (35\%); and c) blends in which the second splinter is longer than the first, comprising nine blends (39\%). A special case in the group b) is presented by INMARSAT, which consists of three splinters and in which the second and the third splinter are equal, but longer than the first. 


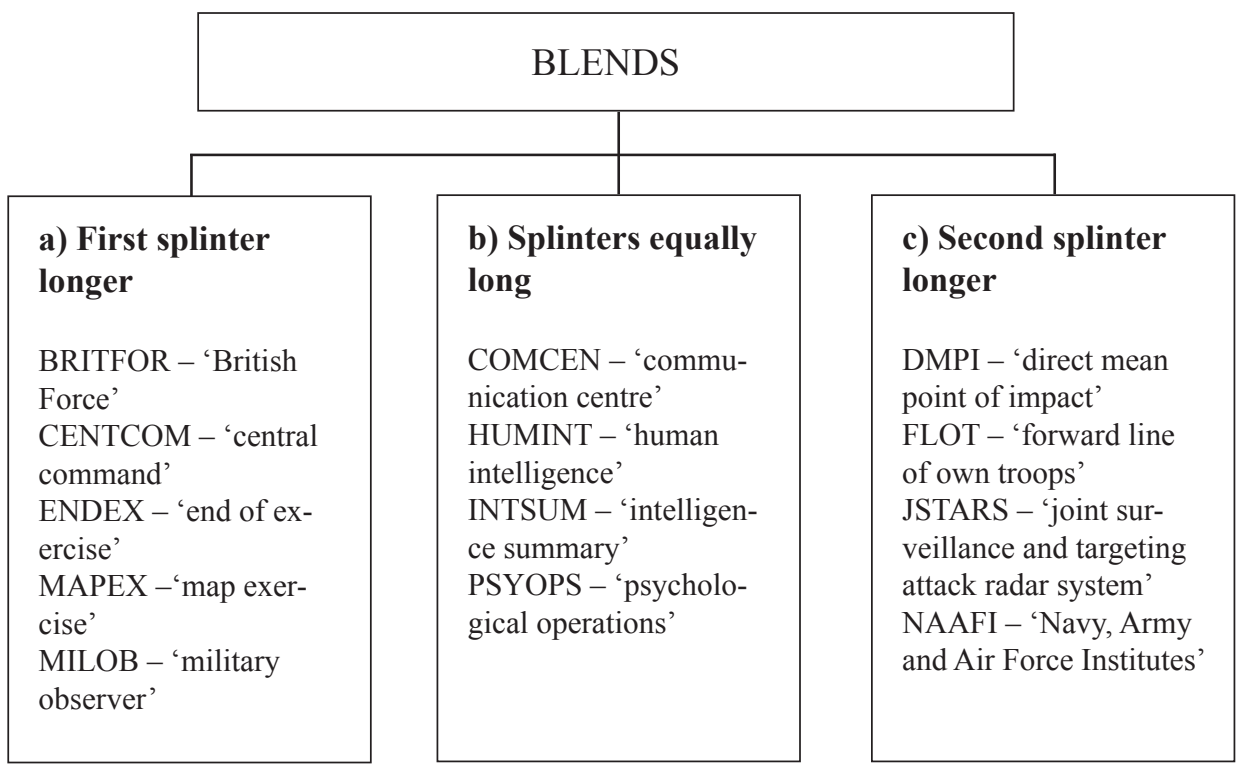

Figure 7. Distribution of blends according to the size of their splinters

Although omission of elements is not common for blends, there are two blends in which omission occurs - 'of' in ENDEX 'end of exercise' and 'radio' in TACSAT 'tactical satellite radio'. We believe this is done in order to make these blends simpler, as no vital information is lost through this omission, while the pronunciation is facilitated.

\subsubsection{Orthographic analysis of clippings and initialisms}

The most common length of abbreviations of the last group examined in our corpus, clippings and initialisms, is six letters, noticed in five examples $(55.56 \%)$, followed by seven letters (22.22\%) and four and eight letters (11.11\% each). The average length of these abbreviations, 6.22 letters, closely corresponds to the most common length, e.g.:

4-letter clipping and initialism

6-letter clippings and initialisms

7-letter clippings and initialisms 8-letter clippings and initialisms
KFOR

COSCOM, DISCOM, ECOMOG, MASINT, SACEUR

MANPADS, SACLANT UNPROFOR

The source phrases of these abbreviations are most commonly four words long (55.56\%), followed by three word source phrases (22.22\%), and two and nine 
words (11.11\% each). The average length of clipping and initialism source phrases is 4.11 words.

2-word clipping and initialism source 'Kosovo Force' phrase

3-word clipping and initialism source 'corps support command' phrases

4-word clipping and initialism source 'man-portable air defence system' phrases

9-word clipping and initialism source 'Economic Community of West African phrase

States cease-fire monitoring group'

As it was stated earlier, splinters are used in the creation of blends and clippings and initials are used in the creation of initialisms (Fandrych 2008b). Since clippings and initialisms use both of these elements, they can be categorized according to the arrangement of these elements into three categories, i.e. into those formed of a) splinter + initial(s); b) splinter + initial + splinter; and c) initial(s) + splinter(s):

\begin{tabular}{|c|c|c|}
\hline & CLIPPINGS AND INITIALISMS & \\
\hline $\begin{array}{l}\text { a) SPLINTER + } \\
\text { INITIAL(S) }\end{array}$ & $\begin{array}{l}\text { b) SPLINTER + INI- } \\
\text { TIAL + SPLINTER }\end{array}$ & $\begin{array}{l}\text { c) INITIAL(S) + } \\
\text { SPLINTER(S) }\end{array}$ \\
\hline $\begin{array}{l}\text { MANPADS - 'man- } \\
\text { portable air defence } \\
\text { system' } \\
\text { ECOMOG - 'Eco- } \\
\text { nomic } \\
\text { Community of West } \\
\text { African States } \\
\text { cease.fire monitoring } \\
\text { group' }\end{array}$ & $\begin{array}{l}\text { COSCOM - 'corpus } \\
\text { support command' } \\
\text { DISCOM - 'divisional } \\
\text { support command' }\end{array}$ & $\begin{array}{l}\text { KFOR - 'Kosovo } \\
\text { Force' } \\
\text { MASINT - 'measure- } \\
\text { ment and signature } \\
\text { intelligence' } \\
\text { SACEUR - 'Supreme } \\
\text { Allied Commander } \\
\text { Europe' } \\
\text { SACLANT - 'Supreme } \\
\text { Allied Commander } \\
\text { Atlantic' } \\
\text { UNPROFOR - 'United } \\
\text { Nations Protection } \\
\text { Force' }\end{array}$ \\
\hline
\end{tabular}

Figure 8. Distribution of clippings and initialisms according to the usage and arrangement of splinters and initials 
A tentative categorization of hybrid abbreviations can be found in López Rúa's work (2004: 127). However, the categorization presented there describes hybrid forms in terms of abbreviation types they incorporate, e.g. acronyms-alphabetisms, abbreviations-clippings, rather than the elements used in their creation. It is our opinion that an analysis of arrangement of elements used in hybrid forms, i.e. splinters and initials, such as that presented in Figure 8 facilitates their analysis as it can be consistently applied to all hybrid forms and explain the processes behind their creation.

\subsection{Morphological analysis}

The goal of the morphological analysis was to analyze the word classes of all abbreviation types and their respective source phrases and the role of lexical and function words in their creation (research questions 3 and 4, cf. §1). In order to provide answers to the research questions the abbreviations are examined according to the following criteria:

- the word class combinations of the abbreviated elements;

- word class of abbreviations compared with the word class of their source phrases in order (to show those abbreviations in which a shift in word class occurs);

- lexical and function source phrase elements used in the creation of abbreviation; and

- the word class of the source phrase elements omitted from the abbreviations.

The same criteria are applied for all abbreviation types and up to five examples are given for all categories. Another goal is to show the lexical function of certain abbreviations and their source phrase constituents. Finally, our aim is to show which source phrase elements are not represented in the abbreviation along with the reasons for their omission.

When considering the word class combinations of the abbreviated elements, the categories of word class patterns are defined by the source phrase elements represented in the abbreviation, and the words that carry the central meaning of the abbreviation. The purpose of this analysis is to show the main patterns used in the creation of each abbreviation type. According to our categorization they can be put into the following categories: Adjective + Noun, Noun + Noun, Noun + Noun + Noun, Noun + Preposition + Noun, Verb + Preposition + Noun. Some abbreviations can be classified into clear-cut categories as a whole, according to the combination of the word class of elements in their source phrases, e.g. RHQ 'regimental headquarters' that may be categorized as Adjective + Noun (Adj + $\mathrm{N})$, and DOB 'date of birth' that may be categorized as Noun + Preposition + Noun $(\mathrm{N}+$ Prep $+\mathrm{N})$. On the other hand, the categories of some abbreviations are determined by source phrase words surrounding the element which carries the central meaning of the abbreviation. Such a word in AAA 'anti-aircraft artillery' 
is 'artillery', as both an abbreviation and its source phrase stand for a certain type of artillery. In IVIS 'intervehicular information system', 'system' holds that central meaning, in BRITFOR 'British Force' that word is 'Force' and in SACLANT, 'Supreme Allied Commander Atlantic', 'Commander' carries the central meaning. Thus, the alphabetism LGOP 'little group of paratroopers' has the word class combination Adjective + Noun + Preposition + Noun $($ Adj $+N+$ Prep $+N)$, but is placed into the category of $\mathrm{Adj}+\mathrm{N}$, since the combination near the word that carries the central meaning, i. e. 'group', is $\mathrm{Adj}+\mathrm{N}$.

The word class combinations for alphabetisms are $\mathrm{N}+\mathrm{N}$ with 10 abbreviations falling into that category, $\mathrm{N}+\mathrm{N}+\mathrm{N}$ with six abbreviations, Adj $+\mathrm{N}$ with 24 abbreviations, $\mathrm{N}+$ Prep $+\mathrm{N}$ with five abbreviations, and $\mathrm{V}+$ Prep $+\mathrm{N}$ with five abbreviations, while four abbreviations do not fall into any of the mentioned categories, as their source phrase elements have a word class combination which does not resemble any other category. The word class combinations for the uncategorized alphabetisms are Adj for IR, Prep + Prep $+\mathrm{N}$ for OOB, $\mathrm{N}+\mathrm{Adj}+$ Prep $+\mathrm{N}$ for OOTW, and $\mathrm{N}+\mathrm{Adj}+\mathrm{N}$ for WMD. Although the pattern Adj $+\mathrm{N}$ is seen in WMD 'weapons of mass destruction', it is not placed into this category because it is the first noun 'weapons' which carries the central meaning. It should be noted that two abbreviations, PO and SAA, have two meanings each and both could belong to two categories, i.e. Adj $+\mathrm{N}$ for 'petty officer' and $\mathrm{N}+\mathrm{N}$ for 'pilot officer', and Adj $+\mathrm{N}+\mathrm{N}$ for 'small arms ammunition' and $\mathrm{N}+$ Prep $+\mathrm{N}$ for 'skill at arms', respectively.

\author{
Alphabetisms \\ Adj $+\mathrm{N}$ AAA, AAM, ABCCC, ATGW, BVR; \\ $\mathrm{N}+\mathrm{N} \quad$ AAR, DSO, EOD, HMS, IO, LZ; \\ $\mathrm{N}+\mathrm{N}+\mathrm{N} \quad$ AAC, CSAR, IFF, MAOT, OSCE; \\ $\mathrm{N}+$ Prep $+\mathrm{N} \quad \mathrm{CINC} / \mathrm{C}$-in-C, DOB, L of C, OOM, POW; \\ $\mathrm{V}+$ Prep + N DOR, KIA, MIA, MID, WIA; \\ Other types IR, OOB, OOTW, WMD.
}

The acronyms of our corpus can be categorized into two main word class combinations, $\mathrm{Adj}+\mathrm{N}$ with 21 abbreviations, $\mathrm{N}+\mathrm{N}+\mathrm{N}$ with 11 abbreviations, and there are four abbreviations that cannot be put into any of the categories, for the same reasons some alphabetisms could not be categorized. The word class combinations for these abbreviations are $\mathrm{N}+$ Prep $+\mathrm{Adj}+\mathrm{N}$ for DIBUA, Adj $+\mathrm{V}+$ Conj $+\mathrm{V}+\mathrm{N}$ for FAARP, $\mathrm{V}+$ Prep + Adj $+\mathrm{N}$ for FIBUA and $\mathrm{V}+$ Prep $+\mathrm{N}$ for ROM.

\title{
Acronyms
}

Adj $+\mathrm{N}$

$\mathrm{N}+\mathrm{N}+\mathrm{N}$

Other types
AWOL, ALARM, BAOR, DMPI, FLOT;

AWACS, JAG, MOAB, NAIAD, SERPACWA;

DIBUA, FAARP, FIBUA, ROM. 
Blends and clippings and initialisms are distributed into two categories - Adj + $\mathrm{N}$ with 14 abbreviations, $\mathrm{N}+\mathrm{N}$ with nine abbreviations for blends, $\mathrm{Adj}+\mathrm{N}$ with three abbreviations, and $\mathrm{N}+\mathrm{N}$ with six abbreviations for clippings and initialisms.

\section{Blends}

Adj + N CENTCOM, ELINT, EUCOM, HUMINT, MEDEVAC; $\mathrm{N}+\mathrm{N} \quad$ AVGAS, BRITFOR, CASEVAC, COMCEN, EMCON.

\section{Clippings and initialisms}

$\mathrm{Adj}+\mathrm{N} \quad$ ANGLICO, COSCOM, DISCOM, KFOR, MASINT;

$\mathrm{N}+\mathrm{N} \quad$ ECOMOG, MANPADS, SACEUR, SACLANT.

The above mentioned categories are more arbitrary for some abbreviations than for others, i.e. some abbreviations fit perfectly into certain categories, while others are placed into their respective categories according to certain parts of their full phrase. Thus, it can be noted that on a general note, the abbreviations of our corpus share two main word class patterns of their source phrases $-\mathrm{N}+\mathrm{N}$ and Adj $+\mathrm{N}$, giving a resultant world class of noun for both patterns.

When the abbreviations of our corpus are divided into word classes, the corpus comprises 109 nouns, five adjectives, two adverbs, one verb, two abbreviations that can be considered both as adjectives and adverbs, and two abbreviations that can be considered both as verbs and nouns. However, some abbreviations are noted to undergo a change in a word class when compared to their source phrases. In other words, the word class of the abbreviation is not the same as that of the source phrase. The word class of four abbreviations (AWOL, BVR, CASEVAC, MEDEVAC) expands from adjective, adverb, noun and noun to adjective/adverb, adjective/adverb, noun/verb and noun/verb, respectively, while one abbreviation (DOR) undergoes a change in word class from noun to verb, as shown in the table below:

Table 1. Abbreviations with different word class than that of their source phrases

\begin{tabular}{|l|l|l|l|l|}
\hline Abbreviation & \multicolumn{1}{|c|}{$\begin{array}{c}\text { Abbreviation } \\
\text { type }\end{array}$} & \multicolumn{1}{|c|}{ Full form } & \multicolumn{1}{|c|}{$\begin{array}{c}\text { Source phrase } \\
\text { word class }\end{array}$} & $\begin{array}{c}\text { Abbreviation } \\
\text { word class }\end{array}$ \\
\hline AWOL & acronym & absent without leave & Adj + Prep $+\mathrm{N}=\mathrm{Adj}$ & Adj/Adv \\
\hline BVR & alphabetism & beyond visual range & $\begin{array}{l}\text { Prep }+ \text { Adj }+\mathrm{N}= \\
\text { Adv }\end{array}$ & Adj/Adv \\
\hline CASEVAC & blend & casualty evacuation & $\mathrm{N}+\mathrm{N}=\mathrm{N}$ & $\mathrm{N} / \mathrm{V}$ \\
\hline DOR & alphabetism & discharge on request & $\mathrm{V}+$ prep $+\mathrm{N}=\mathrm{N}$ & $\mathrm{V}$ \\
\hline MEDEVAC & blend & medical evacuation & $\mathrm{Adj}+\mathrm{N}=\mathrm{N}$ & $\mathrm{N} / \mathrm{V}$ \\
\hline
\end{tabular}

AWOL He's been AWOL for three days (Bowyer 2007)

BVR

We'll have to use our BVR missiles (Bowyer 2007) 
CASEVAC We must arrange a CASEVAC. / He has been CASEVACked (Bowyer 2007)

DOR He was DOR'd from the seal program (Bowyer 2007)

MEDEVAC We need to arrange a MEDEVAC/ He was MEDEVACked because he had malaria (Bowyer 2007)

Apart from various combinations of word classes, we may see that some abbreviations of this corpus even incorporate such combinations which constitute phrases or partial sentences, such as the acronym FIBUA. The form of these abbreviations is relatively simple; they contain a verb in the infinitive form, or present, or past participle and an adverbial of time, and have three or four constituents. Like with Table 1, the context of usage of these abbreviations is given below.

Table 2. List of abbreviations with abbreviated phrases

\begin{tabular}{|c|c|c|c|}
\hline Abbreviation & Full form & $\begin{array}{l}\text { Constituent word } \\
\text { classes }\end{array}$ & $\begin{array}{c}\text { Abbreviation word } \\
\text { class }\end{array}$ \\
\hline DOR & discharge on request & $\mathrm{V} / \mathrm{N}+$ Prep $+\mathrm{N}=\mathrm{N}$ & V \\
\hline FIBUA & fighting in built-up areas & $\begin{array}{l}\mathrm{V} / \mathrm{N}+\text { Prep }+\mathrm{Adj}+\mathrm{N}= \\
\mathrm{N}\end{array}$ & $\mathrm{N}$ \\
\hline KIA & killed in action & $\mathrm{V}+$ Prep $+\mathrm{N}=\mathrm{Adj}$ & Adj \\
\hline MIA & missing in action & Adj/V + Prep + N = Adj & Adj \\
\hline ROM & refuelling on the move & $\mathrm{V}+$ Prep $+\mathrm{Art}+\mathrm{N}=\mathrm{N}$ & $\mathrm{N}$ \\
\hline WIA & wounded in action & Adj $/ \mathrm{V}+$ Prep $+\mathrm{N}=$ Adj & Adj \\
\hline
\end{tabular}

DOR He was DOR'd from the SEAL programme (Bowyer 2007)

FIBUA I am going on a FIBUA course (Bowyer 2007)

KIA The KIA badge was awarded by the government-sponsored Izokukai. (URL 1)

MIA Two sets of MIA remains which were recovered recently in the central province of Quang Tri were airlifted to Hawaii (URL 2)

ROM The primary purpose of ROM is to ensure that the fuel tanks on all combat and fuel-servicing vehicles are topped off before they arrive in the unit's tactical assembly area (URL 2)

WIA A key term used to define combat-injured casualties is the number of wounded in action (WIA) and is the sum of three subgroups (URL 3)

If we look at the constituent phrases of the abbreviations with regard to their lexical properties, abbreviations may be grouped into two categories: abbreviations which contain only lexical words, i.e. nouns, verbs, adjectives and adverbs, and abbreviations which contain both lexical and function words, i.e. prepositions, conjunctions and pronouns. The latter group is further divided into abbreviations in which function words are only a part of source phrases, but omitted from the abbreviation themselves, and those abbreviations in which function words from source phrases are represented. This distribution is illustrated in Figure 9. Thus, the majority of source phrases of this 
corpus do not include function words, while $64 \%$ of those which include function words include those function words in the abbreviation as well.

The omission of elements is more prominent with initialisms than with other two types of abbreviations, and somewhat more with acronyms than alphabetisms. We consider that this is because acronyms are more arbitrary in their creation than alphabetisms, meaning more source phrase elements are omitted to make a certain abbreviation pronounced as a single word. Specifically, six out of 52 alphabetisms (11.5\%) omit certain elements of their source phrase, and those are conjunctions 'and' (as in ABCCC, OSCE and VTOL) and 'or' (in IFF), and prepositions 'of' (in ETA and WMD), 'in' and 'for' (in OSCE).

It should be also noted that the constituents omitted from some abbreviations above are not omitted from other abbreviations. For example, 'in' is omitted from OSCE 'Organization for Security and Cooperation in Europe', but is not omitted from KIA 'killed in action', MIA 'missing in action', WIA 'wounded in action', and MID 'mentioned in Dispatches'. The motivation for the omission of 'in' from OSCE seems to be facilitation of writing, as only the lexical words are used in the abbreviation, while function words, among which is 'in', are omitted to make the abbreviation shorter and more practical to use. Furthermore, while almost all

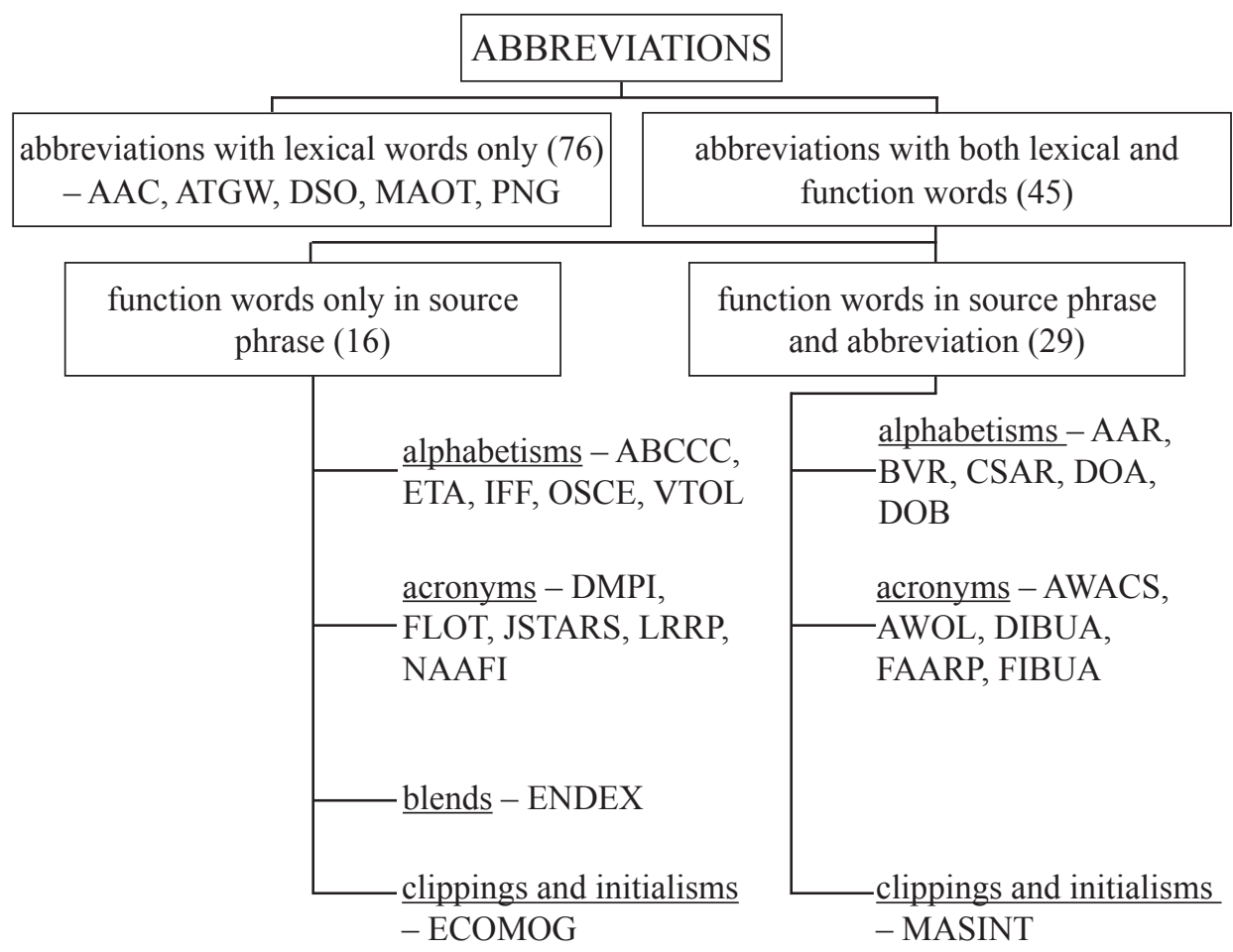

Figure 9. Distribution of abbreviations according to lexical properties of source phrase constituents 
abbreviations with compounds in their source phrases use both parts of the compound, in AAM 'air-to-air missile' preposition 'to' is omitted, presumably for the same reasons as 'in' from OSCE.

The acronyms of the selected corpus omit even more elements. Out of 36 acronyms, $12(32.4 \%)$ omit both lexical and function words. Out of those twelve, function words are omitted from eight acronyms, i.e. prepositions 'of' from DMPI and FLOT and 'in' from SHAPE, the conjunction 'and' from JSTARS, LRRP, NAAFI and NAIAD, and the article 'the' from ROM. Among the lexical words omitted from acronyms, there are four nouns, four verbs and two adjectives. The acronyms which omit lexical words are HARM (in which 'speed' is omitted), HOT ('subsonic', 'guided' and 'fire'), METT-T ('available'), NAIAD ('enzyme' and 'and') and TOW ('launched', 'tracked', 'guided' and 'missile'). However, it should be noted that the omissions of 'speed' from HARM and 'launched', 'tracked' and 'guided' from TOW refer to omission from parts of compounds, rather than individual words.

The fact that five acronyms of our corpus omit lexical words is particularly interesting when related to the fact that they are pronounced as single words. The nature of their pronunciation, coupled with the fact that their source phrases are roughly 1.3 word longer than those of alphabetisms, leads us to the conclusion that acronyms are used to abbreviate terms that would be too inconvenient to abbreviate as alphabetisms, due to their length, and this is often done at the expense of words in the source phrase, both lexical and grammatical. Should the acronyms HARM, NAIAD and TOW include all source phrase elements, the result would be - "HSARM, "METTAT and "NAIEAAD, either rather awkward acronyms or too long to be alphabetisms. Thus, we may conclude that this is a general rule for creation of initialisms; first, all the initial letters are taken and the appropriate type of initialisms is chosen, depending on the number and arrangement of letters, and second, if necessary, elements are omitted in order to make the abbreviation more pronounceable.

Even though omission of elements is not symptomatic of blends, two blends (8.7\%) from our corpus omit certain source phrase elements. Those are ENDEX, which omits the preposition 'of' and TACSAT which omits the noun 'radio'. Like with initialisms, the motivation for this is practicality in pronunciation and writing. The same applies to ECOMOG 'Economic Community of West African States cease-fire monitoring group', which is the only clipping and initialism of this corpus that omits certain elements, although it omits five source phrase elements, both lexical and function words, i.e. 'of', 'West', 'African', 'States' and 'cease-fire'.

Generally speaking, abbreviations follow the pattern of creation: source phrase $\rightarrow$ compound $\rightarrow$ abbreviation. For instance, EOD 'explosive ordnance disposal' has the phrase 'disposal of explosive ordnance' as its starting point, which is then shortened into a compound, and later abbreviated into EOD. However, some phrases "skip" one stage of their creation, i.e. they do not have the compound form, but immediately become abbreviations. These abbreviations are shown below, along with their source phrases and their potential compound forms: 
Table 3. Examples of source phrases directly abbreviated without compounding

\begin{tabular}{|l|l|l|}
\hline SOURCE PHRASE & POSSIBLE COMPOUND & ABBREVIATION \\
\hline date of birth & "birth date & DOB \\
\hline estimated time of arrival & "estimated arrival time & ETA \\
\hline line of communication & "communication line & L of C \\
\hline order of march & "march order & OOM \\
\hline $\begin{array}{l}\text { Organization for Security } \\
\text { and Cooperation in Europe }\end{array}$ & $\begin{array}{l}\text { "Security and Cooperation } \\
\text { in Europe Organization }\end{array}$ & OSCE \\
\hline prisoner of war & "war prisoner & POW \\
\hline $\begin{array}{l}\text { weapons of mass destruc- } \\
\text { tion }\end{array}$ & "mass destruction weapons & WMD \\
\hline direct mean point of impact & "direct mean impact point & DMPI \\
\hline
\end{tabular}

\section{Conclusion}

The aim of our work was to show various orthographic and morphological properties of abbreviations of English military terminology, in order to provide a clearer picture of abbreviations in this particular part of the lexicon. In the selected corpus, two major abbreviation types were found: initialisms, which comprise alphabetisms and acronyms, and blends. In addition, an abbreviation type which is a hybrid form of clippings and initialisms was also recorded. Among the abbreviations, the most numerous were initialisms, comprising 89 out of 121 abbreviations, followed by blends with 23 examples and clippings and initialisms with 9 examples.

On the orthographic level, the length of alphabetisms ranges from two to five letters, and the most common are 3-letter alphabetisms, with the length of their source phrases ranging from one to seven letters and the most common length being three words. The acronyms' length ranges from three to eight letters with the most common length of four letters. The source phrase length ranges from three to eight words, with 4-word source phrases as most common. The length of blends ranges from five to eight letters, with 6-letter blends being the most common. Their source phrases are mostly two words long, with three examples of 3-word source phrases. The length of hybrid forms of clippings and initialisms ranges from four to eight letters, with six letters being the most common length. The length of their source phrases ranges from two to nine words, with four words as the most common length.

Majority of initialisms follow the regular patterns of creation, i.e. one letter per one source phrase constituent. However, $25 \%$ of abbreviations use 2-letter initials or omit certain elements, and thus do not follow the regular pattern. In fact, when comparing the most common length of initialisms and their respective source phrases one can see the discrepancy between the two. This shows that the complete language economy is not a dominant tendency in initialisms, i.e. that majority of them do not omit all elements that could be regarded as unnecessary. 
In majority of blends a source phrase constituent is represented by a splinter, and the second splinter tends to be the larger one, although this pattern is not significantly more dominant (39\% cases) than the other two - first splinter larger and splinters being equal in size. Since the analysis of hybrid forms in this corpus could not have gone into so much detail as that of other abbreviation types, only their patterns of elements used were determined - splinter + initial(s), splinter + initial + splinter, and initial(s) + splinter(s).

On the morphological level, 109 abbreviations are nouns, five are adjectives, two are adverbs, one is a verb, two abbreviations are both nouns and verbs, and two are both adjectives and adverbs. The predominant patterns of abbreviations source phrases are Adjective + Noun and Noun + Noun, although the patterns of source phrases are rather diverse. The abbreviations tend to have the same word class as their source phrases, except for five abbreviations in which a change in word class was noted.

It was noted that $63 \%$ of abbreviations in our corpus include only lexical words, while $37 \%$ use both lexical and function words, which is a significant ratio. Among the latter, function words are used in both the abbreviations and their source phrases in $64 \%$ abbreviations, while in the remaining $36 \%$ function words are used only in the source phrases. Omission of elements is particularly prominent with initialisms, especially acronyms, some of which omit both lexical and function source phrase elements, while alphabetisms omit only function words. Omission of elements is noted among blends and clippings and initialisms, although not as often as with initialisms. The reasons for these omissions are assumed to be the facilitation of pronunciation and writing for all abbreviations.

The abbreviations in general are a very diverse and flourishing part of the lexicon, and it is in the military lexicon where the necessity for practical abbreviations becomes apparent, as many abbreviations are found to omit certain elements, presumably to facilitate their usage.

\section{References}

Algeo, John (ed.) (1991) Fifty Years Among the New Words. Cambridge: Cambridge University Press. Bauer, Laurie (2003) "The Productivity of (Non-)productive Morphology". Rivista di Linguistica, 15 (1), 7-16.

Bowyer, Richard (2007) Dictionary of Military Terms, $3^{\text {rd }}$ ed. London: A\&C Black Publishers Ltd.

Cannon, Garland (1989) "Abbreviations and Acronyms in English Word-Formation". American Speech 64 (2), 99-127.

Crowley, Ellen T., and Hellen E. Sheppard (1987) Acronyms, Initialisms \& Abbreviations Dictionary, $12^{\text {th }}$ ed. Detroit: Gale.

Crystal, David (1995) The Cambridge Encyclopaedia of the English Language. Cambridge, Cambridge University Press.

Fandrych, Ingrid (2008a) "Pagad, Chillax and Jozi: A Multi-Level Approach to Acronyms, Blends, and Clippings". Nawa Journal of Language and Communication 2 (2), 71-88.

Fandrych, Ingrid (2008b) "Submorphemic elements in the formation of acronyms, blends and clippings”. Lexis 2: Lexical Submorphemics / La submorphémique lexicale, 105-123. 
Fischer, Roswitha (1998) Lexical change in present-day English. Tübingen: Gunter Narr.

Gries, Stefan Th. (2004a) "Shouldn't it be breakfunch? A quantitative analysis of the structure of blends". Linguistics 42 (3), 639-667.

Gries, Stefan Th. (2004b) "Isn't that fantabulous? How similarity motivates intentional morphological blends". In: Achard, Michel and Suzanne Kemmer (eds.) Language, culture, and mind. CA: CSLI, Stanford, 415-428.

Harley, Heidi (2006) English Words: A Linguistic Introduction. Oxford: Blackwell Publishing.

Jackson, Howard and Etienne Zé Amvela (2005) Words, Meaning and Vocabulary. London: Continuum.

Kreidler, Charles W. (1979) "Creating new words by shortening”. Journal of English Linguistics 13, 24-36.

Lehrer, Adrienne (1998) "Scapes, Holics and Thons: The Semantics of English Combining Forms". American Speech 73, 3-28.

Lehrer, Adrienne (2007) "Blendalicious". In: Munat, Judith (ed.) Lexical Creativity. Text and Context. Amsterdam: John Benjamins, 115-133.

López Rúa, Paula (2004) “Acronyms \& Co.: A typology of typologies”. Estudios Ingleses de la Universidad Complutense 12, 109-129.

López Rúa, Paula (2006) "Non-Morphological Word Formation”. In: Encyclopedia of Language and Linguistics $\left(2^{\text {nd }}\right.$ ed.), Vol. 2. Oxford: Elsevier, 675-678.

López Rúa, Paula (2007) "Keeping Up with the Times: Lexical Creativity in Electronic Communication". In: Munat, Judith (ed.) Lexical Creativity. Text and Context. Amsterdam: John Benjamins, $137-159$.

Plag, Ingo (2003) Word-formation in English. Cambridge: Cambridge University Press.

Quirk, Randolph, Sidney Greenbaum, Geoffrey Leech and Jan Svartvik (1985) A Comprehensive Grammar of English. London: Longman.

Sheppard, Hellen E., and Julie E. Towell (1987) International Acronyms, Initialisms \& Abbreviations Dictionary, $2^{\text {nd }}$ ed. Detroit: Gale.

Stockwell, Robert and Donka Minkova (2001) English Words: History and Structure. Cambridge: Cambridge University Press.

\section{Internet sources}

URL 1 - http://www.imperialjapanmedalsandbadges.com/kia.html (Accessed on 13 April 2012)

URL 2 - http://www.theodoresworld.net/archives/vietnam_vets/ (Accessed on 13 April 2012)

URL 3 - http://www.dtic.mil/cgi-bin/GetTRDoc?AD=ADA480496 (Accessed on 13 April 2012) 


\section{Appendix}

\section{Initialisms}

\begin{tabular}{|c|c|}
\hline Abbreviation & Full form \\
\hline AAA & anti-aircraft artillery \\
\hline AAC & Army Air Corps \\
\hline AAM & air-to-air missile \\
\hline AAR & after action review \\
\hline $\mathrm{ABCCC}$ & airborne command, control and communications \\
\hline ATGW & anti-tank guided weapon \\
\hline BVR & beyond visual range \\
\hline $\mathrm{CINC} / \mathrm{C}$-in-C & 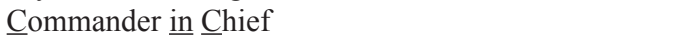 \\
\hline CSAR & combat search $\underline{\text { and }}$ rescue \\
\hline DOA & dead on arrival \\
\hline DOB & date of birth \\
\hline DOR & discharge on request \\
\hline DSO & defensive systems officer. \\
\hline ECCM & electronic counter- counter measures \\
\hline EOD & explosive ordnance disposal \\
\hline ETA & estimated time of arrival \\
\hline GPS & Global Positioning $\underline{\text { System }}$ \\
\hline HMS & 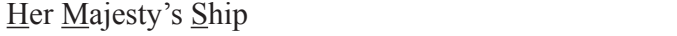 \\
\hline IFF & identification friend or foe \\
\hline IO & intelligence officer \\
\hline IR & infrared \\
\hline KIA & killed in action \\
\hline LCAC & landing craft air cushioned \\
\hline LGOP & little groups of paratroopers \\
\hline L of C & line of communication \\
\hline LZ & landing zone \\
\hline MAOT & mobile air operations team \\
\hline MIA & missing in action \\
\hline MID & Mentioned in Dispatches \\
\hline $\mathrm{NCO}$ & non-commissioned officer \\
\hline OMG & operational manoeuvre group \\
\hline OOB & out of bounds \\
\hline OOM & order of march \\
\hline OOTW & operations other than war \\
\hline OSCE & Organization for $\underline{\text { Security and }}$ Cooperation in Europe \\
\hline PMC & private military company \\
\hline PNG & passive night goggles \\
\hline PO & 1. petty officer 2 . pilot officer \\
\hline POL & petrol, oil, lubricants \\
\hline POW & prisoner of war \\
\hline QRA & quick reaction alert \\
\hline RAC & Royal Armoured Corps \\
\hline RAF & Royal Air Force \\
\hline RHQ & regimental headquarters \\
\hline $\mathrm{R} \& \mathrm{R}$ & rest and recuperation \\
\hline SAA & 1. $\underline{\text { small }}$ arms ammunition 2 . skill at arms \\
\hline SAS & $\underline{\text { Special Air Service }}$ \\
\hline VTOL & vertical take-off and landing \\
\hline
\end{tabular}




\begin{tabular}{|l|l|}
\hline WIA & wounded $\underline{\text { in }}$ action \\
WMD & weapon(s) of $\underline{\text { mass }}$ destruction \\
WVR & within visual range \\
XO & executive officer \\
\hline
\end{tabular}

Acronyms

\begin{tabular}{|c|c|c|}
\hline Abbreviation & Full form & Pronunciation \\
\hline ANGLICO & air naval gunfire liaison company & 'æyglı, kəv \\
\hline ALARM & air-launched antiradiation missile & a'la:m \\
\hline AWACS & Airborne Warning and Control System & 'erwæks \\
\hline AWOL & absent without leave & 'erwpl \\
\hline DMPI & direct mean point of impact & 'dimpi \\
\hline DIBUA & defence in built-up areas & 'dibuə \\
\hline FAARP & forward arming and refuelling point & fa:p \\
\hline FIBUA & fighting in built- $\underline{u}$ p areas & 'fibə \\
\hline FLOT & forward line of own troops & flpt \\
\hline FROG & free rocket over-ground & frog \\
\hline HALO & high altitude low opening & 'heIləo \\
\hline HARM & high-speed anti-radiation missile & ha:m \\
\hline HEAT & high explosive anti-tank & hi:t \\
\hline HESH & high explosive squash-head & hes \\
\hline HOT & high subsonic, optically guided, tube fire & hpt \\
\hline IAAG & improvised anti-armour grenade & 'aræg \\
\hline IVIS & intervehicular information system & 'arvis \\
\hline JAG & judge adjutant general & dzæg \\
\hline JDAM & joint direct attack munition & 'dzerdæm \\
\hline JSTARS & 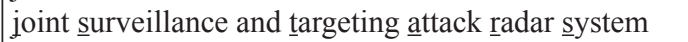 & 'dzer sta:z \\
\hline LRRP & long-range reconnaissance and patrolling & 13:p \\
\hline MASH & mobile army surgical hospital & $m æ \int$ \\
\hline METT-T & mission, enemy, terrain, troops available, time & met 'ti: \\
\hline MILES & multiple integrated laser engagement system & mailz \\
\hline MOAB & Massive Ordnance Airburst Bomb & 'məvæb \\
\hline NAAFI & $\underline{\text { Navy, }}$ Army and $\underline{\text { Air Force Institutes }}$ & 'næfi \\
\hline NAIAD & 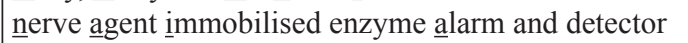 & naiæd \\
\hline NATO & North Atlantic Treaty Organization & 'neitəu \\
\hline ROM & refuelling on the move & $\mathrm{rbm}$ \\
\hline SACLOS & semi-automatic commandline of $\underline{\text { sight }}$ & 'sæklps \\
\hline SALUTE & Size, Activity, Location, Unit, Time, Equipment & sə'lu:t \\
\hline SEAL & sea, air, land & \\
\hline SERPACWA & $\begin{array}{l}\text { skin exposure reduction paste against chemical war- } \\
\text { fare agents }\end{array}$ & sərpækwa \\
\hline SHAPE & Supreme Headquarters, $\underline{\text { Allied }}$ Powers in Europe & Serp \\
\hline TEWT & tactical exercise without troops & 'tju:t \\
\hline TOW & tube-launched, optically-tracked, wire-guided & tov \\
\hline WAC & weapons aiming computer & wæk \\
\hline
\end{tabular}




\section{Blends}

\begin{tabular}{|c|c|c|}
\hline Abbreviation & Full form & Pronunciation \\
\hline AVGAS & aviation gasoline & 'ævgæs \\
\hline BRITFOR & British Force & 'britfo: \\
\hline CASEVAC & casualty evacuation & 'kæzıvæk \\
\hline CENTCOM & central command & 'sentkpm \\
\hline COMCEN & $\overline{\text { communication centre }}$ & 'kpmsen \\
\hline ELINT & electronic intelligence & 'i:lint \\
\hline EMCON & $\underline{\text { emission } \underline{\text { control }}}$ & 'emkpn \\
\hline ENDEX & end of exercise & 'endeks \\
\hline EUCOM & European Command & 'ju:kpm \\
\hline HUMINT & $\underline{\text { human intelligence }}$ & 'hju:mint, ,h $\mathrm{h}$ mint \\
\hline INMARSAT & international maritime satellite & 'Inma:sæt \\
\hline INTSUM & intelligence summary & 'Ints $\Lambda \mathrm{m}$ \\
\hline MAPEX & $\underline{\text { map }}$ exercise & 'mæpek \\
\hline MEDEVAC & $\underline{\text { medical evacuation }}$ & 'medivæk \\
\hline MILOB & $\underline{\text { military observer }}$ & 'mailpb \\
\hline OPFOR & opposing forces & 'pp'fo: \\
\hline OPSCHED & operation schedule & ,pp $\int e d$ \\
\hline PACOM & $\underline{\text { Pacific Command }}$ & 'pækpm \\
\hline PSYOPS & $\underline{\text { Psychological operations }}$ & 'samps \\
\hline PSYWAR & psychological warfare & 'saiwっ: \\
\hline SATNAV & satellite navigation & 'sætnæv \\
\hline STRATCOM & $\underline{\text { strategic command }}$ & 'strætkpm \\
\hline TACSAT & $\underline{\text { tactical satellite radio }}$ & 'tæksæt \\
\hline
\end{tabular}

\section{Clippings and initialisms}

\begin{tabular}{|c|c|c|}
\hline Abbreviation & Full form & Pronunciation \\
\hline COSCOM & corps support command & 'kpskpm \\
\hline DISCOM & divisional support command & 'diskkpm \\
\hline ECOMOG & $\begin{array}{l}\text { Economic Community of West African States cease- } \\
\text {-fire monitoring group }\end{array}$ & I:'kpmog \\
\hline KFOR & Kosovo Force & 'kei fo: \\
\hline MANPADS & man-portable air defence system & 'mænpædz \\
\hline MASINT & measurement and signature intelligence & 'mæzint \\
\hline SACEUR & Supreme Allied Commander Europe & 'sæk3: \\
\hline SACLANT & Supreme $\underline{\bar{A}}$ llied $\underline{\bar{C}}$ ommander Atlantic & 'sæklænt \\
\hline UNPROFOR & United Nations Protection Force & $\Lambda$ n'prəひ, fo: \\
\hline
\end{tabular}

Frane MALENICA is a graduate of English Department, University of Zadar and is currently an independent researcher and a freelance English lecturer and translator. He obtained his MA in English philology in 2011. His research interests include lexicology, lexicography, morphology and crosslinguistic influence.

Address: Frane Malenica, mag. philol. angl., Šibenska 4e, 23000 Zadar, Croatia [email: fmalenica29@gmail.com] 
Ivo FabiJanić works as an academic in English Studies Department, University of Zadar, Croatia. He obtained his $\mathrm{PhD}$ degree in 2009 with the thesis entitled Anglicisms in Russian and Croatian Economic Terminology. His research papers are related to contact linguistics (English-RussianEnglish, English-Croatian-Croatian contacts), lexicology and lexicography of English, Russian and Croatian language.

Address: Ivo Fabijanić, PhD., assistant professor; English Studies Department; University of Zadar; Obala kralja Petra Krešimira IV., 2; 23000 Zadar, Croatia. [e-mail: ivo.fabijanic@unizd.hr] 
